Research Article

\title{
Construction and Optimization of Higher Education Management System Based on Internet Video Online Technology
}

\author{
Jinhua Liu $\mathbb{D}$, Caiping Wang, and Yanhua Wu \\ Jiangsu Vocational College of Agriculture and Forestry, Jurong 212400, China \\ Correspondence should be addressed to Jinhua Liu; liujinhua@jsafc.edu.cn
}

Received 26 February 2021; Revised 25 March 2021; Accepted 1 April 2021; Published 16 April 2021

Academic Editor: Shah Nazir

Copyright ( 92021 Jinhua Liu et al. This is an open access article distributed under the Creative Commons Attribution License, which permits unrestricted use, distribution, and reproduction in any medium, provided the original work is properly cited.

\begin{abstract}
With the rapid development of information technology, the integration of multimedia technology and traditional institutional systems is increasing. However, at present, the establishment and construction of the higher education system in China are not proportional, the function is vague, and the communication efficiency is not high. The reason for this phenomenon is that the traditional higher education management system has been unable to meet the needs of information society and information integration and it is unable to meet the increasing demand for higher education. Therefore, based on the above reasons, it is very important and has long-term strategic significance to establish an efficient and convenient higher education management system based on today's Internet multimedia technology in a timely and reasonable manner. This paper analyzes the current status of the higher education management system and the problems that are arisen and proposes a three-dimensional integrated management system based on the innovation of Internet multimedia technology. At the same time, aiming at the urgent needs of the current lifelong education of higher education, a reasonable system of higher education diversion is established to focus on solving the phenomenon of imbalanced proportions, ambiguous functions, and low communication efficiency. In the final practical part of this paper, the system model of the three-dimensional integrated education system and the corresponding practical solution to the education diversion are given. After discussion, it has practical application value. The results of the research have shown the effectiveness of the proposed study.
\end{abstract}

\section{Introduction}

With the improvement of China's economy and the implementation of the education first policy, the popularization of higher education has made great achievements in China. So far, the scale of China's higher education has reached the world's first level [1]. However, with the increasing popularity and development of higher education, the higher education system exposed in the process is too aging [2], and the quality, structure, and corresponding educational benefits of higher education development are increasingly prominent [3]. Furthermore, rationalization of communication efficiency has become an important topic in the construction of higher education systems today [4].

There are a lot of research studies and analyses on the system construction of higher education. The analysis mainly focuses on the design of higher education curriculum, the construction of higher education resources sharing, the research of higher education teaching mode, and the corresponding higher education management and evaluation mechanism [5]. The Higher Education Technical Cooperation Management Committee has systematically proposed the theory and practice of higher education, which systematically introduces the form and practice of the higher education system, but due to its age, its corresponding theory is no longer applicable in today's information society [6]. But its focus is on the teaching of online courses [4], which focuses on network distance teaching, so it has certain limitations, and at the same time, the implementation plan of the education diversion system is not given [7]. Foreign countries' construction of higher education systems is limited to their own educational traditions. Similar to Ralph's "Sponsored Mobility and Competitive Mobility and School Education System" proposal, this analysis believes that the school's teaching system has two modes, namely, sponsored mobility and competitive mobility [8], and it is believed that sponsorship mobility is dominant in the UK education system, 
so its theory has no practical significance for the construction of China's education system [9]. It has also proposed the construction of an education system based on the current situation in the United States, which emphasizes the factors affecting higher education such as class mobility, but it has no practical significance in inspiring China's higher education or modern higher education [10].

Based on the current teaching situation, this paper proposes a three-dimensional integrated teaching system, proposes a three-in-one higher education system in combination with today's computer network multimedia technology, and introduces a quality management system in the higher education system [11] to realize the scientific management and standardized handling of the higher education system. Finally, the paper puts forward the actual model of the higher education management system in the practice part and conducts in-depth analysis and discussion [12].

This article is organized as follows. In Section 2, the key research works in the area are presented, which mainly analyzes the current problems in higher education and the relationship between computer technology and the current education system [13]. Section 3 mainly analyzes the principle of the three-dimensional integrated quality management system proposed in this paper and the corresponding application of computer network multimedia technology. Section 4 mainly constructs and analyzes the actual model of the higher education system based on multimedia technology proposed in this paper. Section 5 summarizes the content of this article [14].

\section{Related Work}

Research specifically analyzes the problems existing in the current higher education management system in China and analyzes them in detail [15]. At the same time, this section will specifically analyze the multimedia technology tools currently used in education to provide technical support and theoretical support for the follow-up higher education management mechanism. Figure 1 shows the framework of the traditional higher education management system. Corresponding to Figure 1, we can see that the traditional higher education management system is too mechanized, too complicated, and lengthy [16].

\subsection{Analysis of Problems in Traditional Higher Education} System. The comprehensive survey and analysis can summarize the problems existing in the current higher education management system as follows [17].

\subsubsection{Higher Education Teaching Infrastructure} Management. In this respect, there is a situation of uneven distribution of resources, which leads to the increasing distribution of educational resources in developed regions and the growing gap between infrastructure resources in underdeveloped regions and developed regions, especially in online higher education. The most obvious form is the low computer penetration rate in underdeveloped areas and at the same time limited by the speed of network transmission. The quality and stability of distance education teaching information such as broadband multimedia telecommunication networks are very poor, which leads to higher education [18]. The serious mismatch of teaching resources and the interaction and function of interactive technical media cannot play a role. At the same time, in terms of infrastructure construction management, better and better infrastructure funding has flowed to the place where the original teaching infrastructure is good, resulting in a large amount of waste of resources, and higher education institutions in underdeveloped regions cannot further improve their teaching condition.

\subsubsection{Higher Education Teaching Resource Management.} In the direction of teaching resource management that is too old, the relevant textbooks of higher education and the corresponding curriculum practice still stay in the existing teaching system, the teaching resources are equipped, and the use of reasonable information is not enough. This has caused a huge waste of human resources and time costs.

\subsubsection{Higher Education Teacher Team Management System.} There are serious problems in the distribution of teachers' resources. The teacher resources in different regions are seriously dysfunctional. The teaching ability of many teachers cannot match the teaching content and student needs. The fundamental reason is that there is a lack of reasonableness. And the teacher training management keeps pace with the times. It is impossible to be reasonable and efficient in the management of the title of teachers.

\subsubsection{The Lack of Higher Education Diversion System.} There are too many people in China who urgently need higher education, but because the level of people and needs are different, the traditional higher education management system is no longer applicable. This led to the diversion system in the higher education management system, but the domestic research is too little in theoretical construction. At the same time, the research content is single and not comprehensive. When the specific research is carried out, there are many descriptions, but the mechanism analysis is too small. The method is also too qualitative, and there are fewer persuasive examples. The specific corresponding framework for the problems in the higher education diversion system is shown in Figure 2.

Based on the abovementioned problems in the higher education management system, the performance of different categories and corresponding details can be summarized in the reason tree shown in Figure 3.

\subsection{Analysis of the Relationship between Internet Multimedia} Technology and Higher Education. Internet-based multimedia technology has gradually integrated into the higher education system. Before the relevant research, this paper made a questionnaire on the acceptance of relevant information about students and teachers in the integration of 


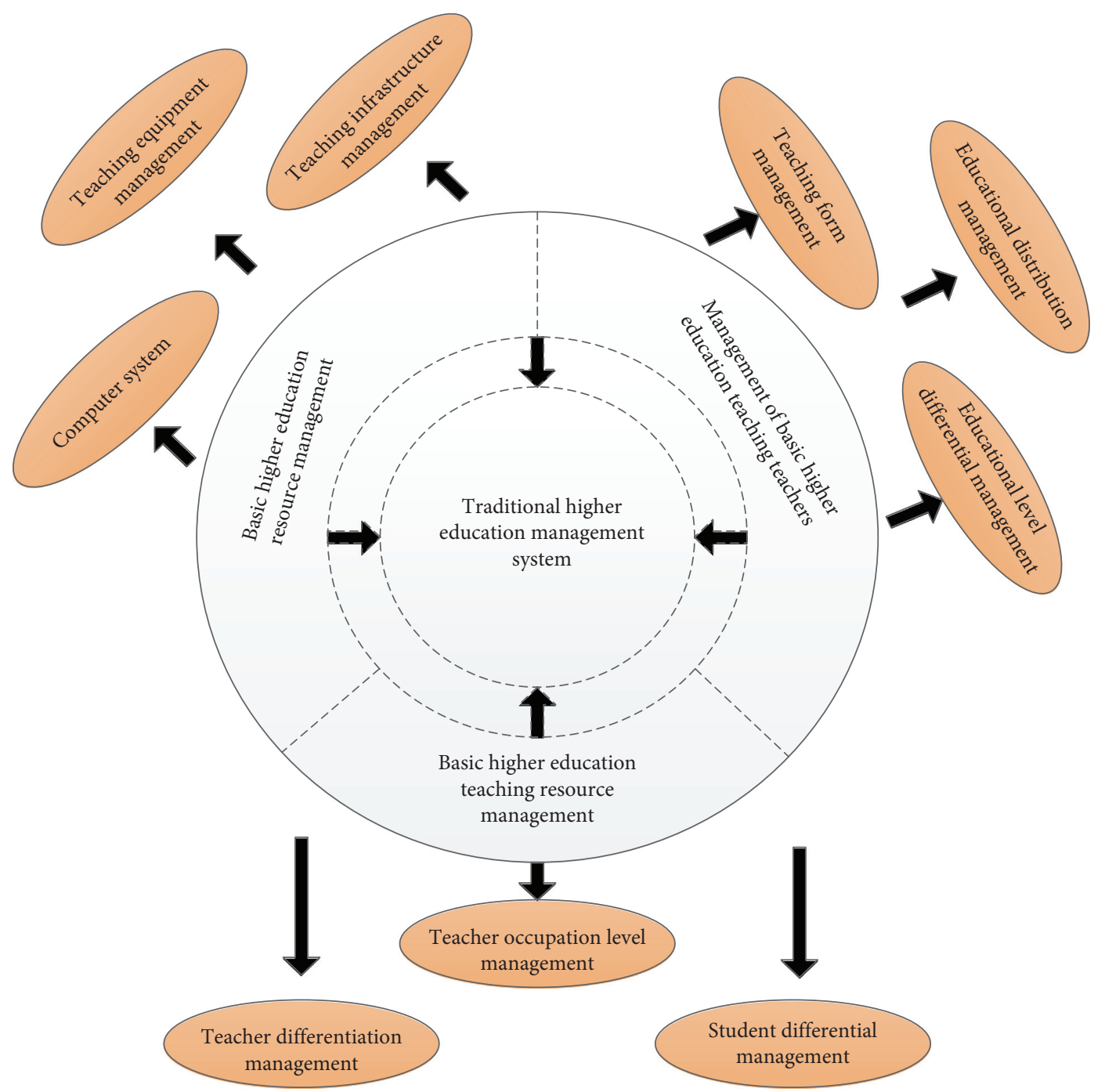

FIgURE 1: The framework of the traditional higher education management system.

information technology into the higher education system. The corresponding survey sample is a total of 2,000 colleges and universities in the east and the west, which fully guarantees the regionality of the sample and the sample size. The corresponding data table is shown in Table 1.

\subsubsection{Internet Multimedia Education Technology.} Internet multimedia teaching technology is limited to sound, text, and images, as well as the defects of recording through books. Multimedia education technology has greatly improved the informationization degree of education. Internet multimedia education technology is a convenient and rapid integration of a variety of media, and its corresponding educational and teaching content is presented in a more abundant form. Its main advantages are mainly as follows:

(1) Internet-based education and teaching technology can synthesize and stimulate a variety of media, which leads to management changes in textbooks in the higher education management system. For example, traditional textbook materials can become auxiliary textbooks under informatization, such as multimedia textbooks, teaching materials, and some hypertext technology of sound, image, and animation synthesis.

(2) Based on the convenience of Internet technology, the real-time opening of education and teaching can be realized. At the same time, the management system of higher education is also conducive to the release and timely delivery of information. In terms of the details of its implementation, it is dedicated to teaching. The information website can be updated and supplemented with teaching resources and new management trial methods at any time.

(3) The emergence of information technology teaching is conducive to the change of students' learning styles. Therefore, it also realizes the management of students' learning methods in the higher education management system to a certain extent. In this process, multimedia computer technology has become an auxiliary tool for students to conduct self-learning management, and it has become a 


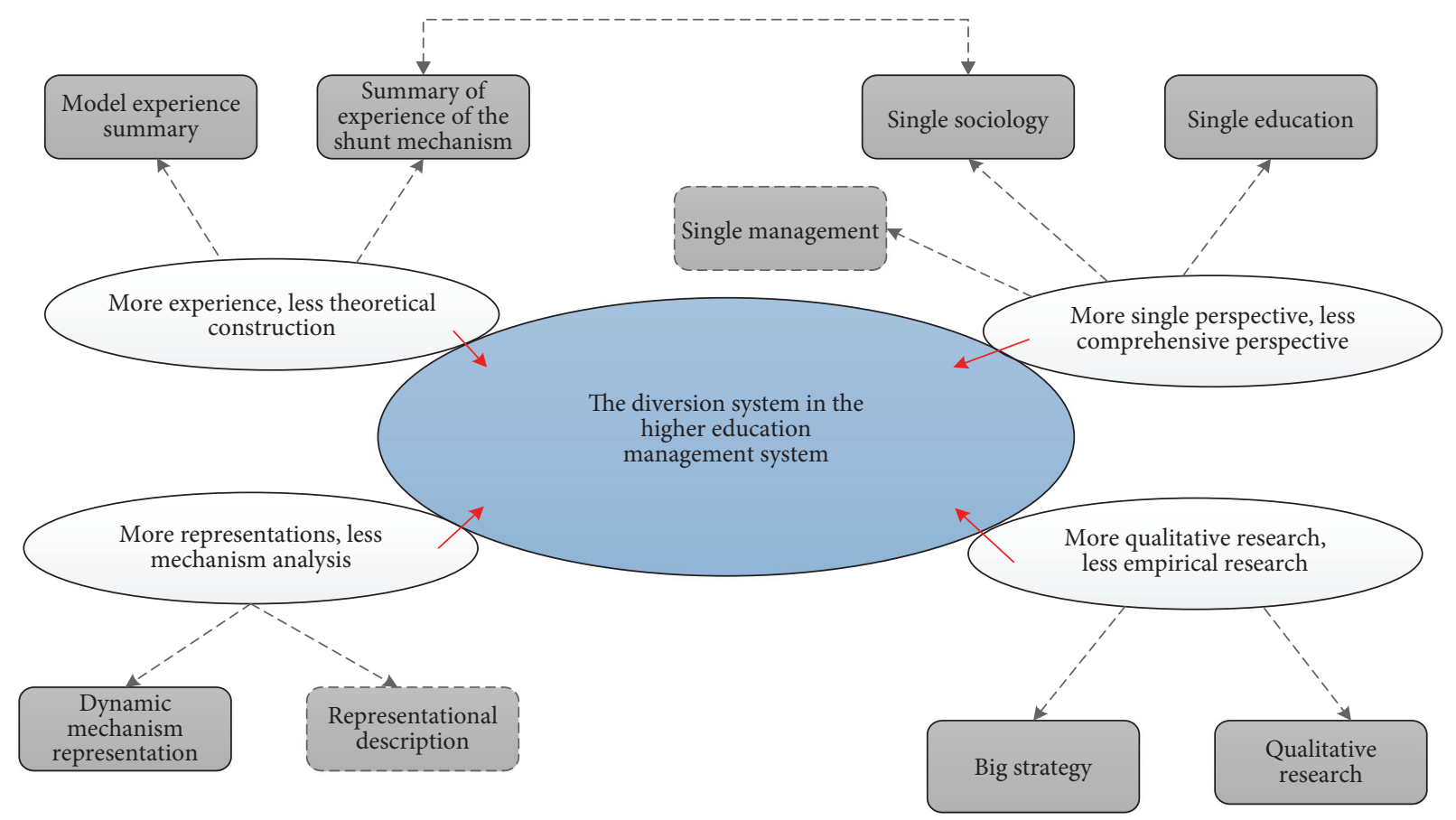

Figure 2: Specific corresponding framework for the problems in the higher education diversion system.

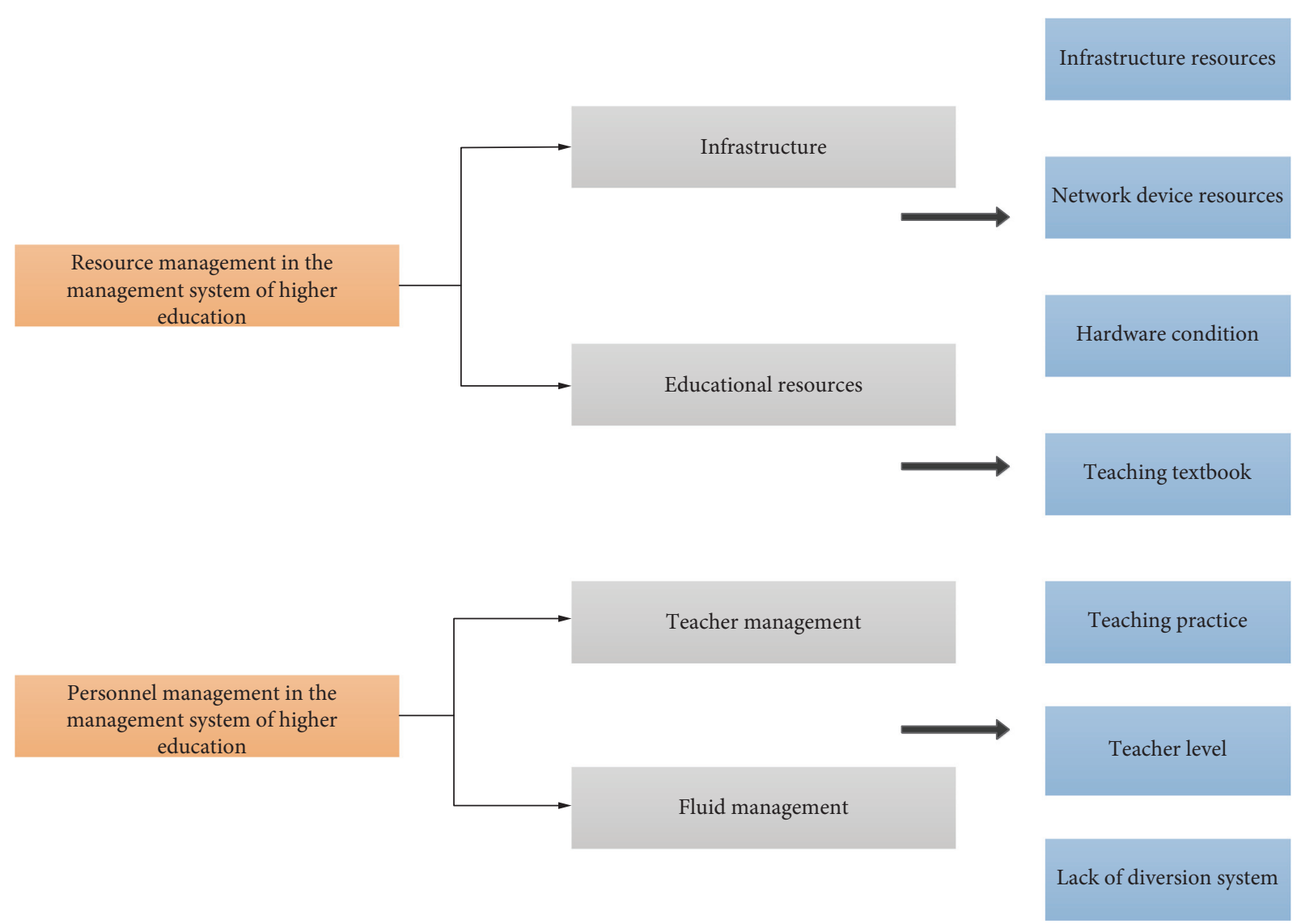

FIGURE 3: The performance of different categories and corresponding details. 
TABLE 1: The statistics of the textbooks used in traditional English translation.

\begin{tabular}{lccc}
\hline $\begin{array}{l}\text { Total number of } \\
\text { samples }\end{array}$ & Option & Proportion & Conclusion \\
\hline \multirow{4}{*}{2000} & $\begin{array}{c}\text { Fully accepted and expect a good } \\
\text { form to appear }\end{array}$ & 80 & \\
& $\begin{array}{l}\text { Accept but stay optimistic } \\
\text { No feeling is not important }\end{array}$ & 15 & On the whole, I tend to look forward to the emergence of a new \\
& $\begin{array}{c}\text { Do not expect to feel the current } \\
\text { problem }\end{array}$ & 4 & higher education management system
\end{tabular}

student's performance tool, communication tool, and research tool. At the same time, as a part of management in higher education, informatization makes the student management part more efficient.

(4) Informatization technology makes the management of teacher-student interaction module more vivid and timely. Education and teaching are essentially the interaction between teachers and students. The traditional mode of higher education is almost limited to verbal communication and is subject to the time and space of communication. The main applications include hierarchical teaching, cooperative teaching, and feedback teaching.

Based on the above analysis, the corresponding frame diagram is shown in Figure 4.

\section{Construction of Higher Education Management System Based on Internet Multimedia Technology}

3.1. Three-Dimensional Integrated Education Quality Management System Based on Multimedia Technology. This paper proposes a quality management system based on multimedia online technology, combined with the outcome management system evaluation system of teaching quality which effectively guarantees and continuously improves the management of education quality mode. The corresponding frame diagram is shown in Figure 5.

According to the optimal information gain attribute, the data classification and map feature reconstruction are carried out, and the univariate time series of big data time series is constructed as $\left\{x_{n}\right\}$. The length of the data sample is $N$, and the time series is reconstructed by phase space. It is obtained that the high-dimensional space trajectory vector of big data's characteristic distribution is described as follows:

$$
\mathbf{L}=\left[\begin{array}{c}
x_{1}^{T}, \\
x_{2}^{T}, \\
\vdots \\
x_{N}^{T},
\end{array}\right]=\left[\begin{array}{cccc}
x_{1}, & x_{1+\tau}, & \ldots, & x_{1+(m-1) \tau}, \\
x_{2}, & x_{2+\tau}, & \ldots, & x_{2+(m-1) \tau}, \\
\vdots & \vdots & \ddots, & \vdots \\
x_{N-1}, & x_{N-1+\tau}, & \ldots, & x_{N-1+(m-1) \tau},
\end{array}\right],
$$

where in the embedding dimension is $m$ and the time delay is $\tau$, and in the large data distribution space, the trajectory matrix $\mathbf{L}$ of high-dimensional space is decomposed with the unitary matrix decomposition method. The $\mathbf{L}=\mathbf{U} * \mathbf{S} * \mathbf{C}$ is obtained by using the unitary matrix

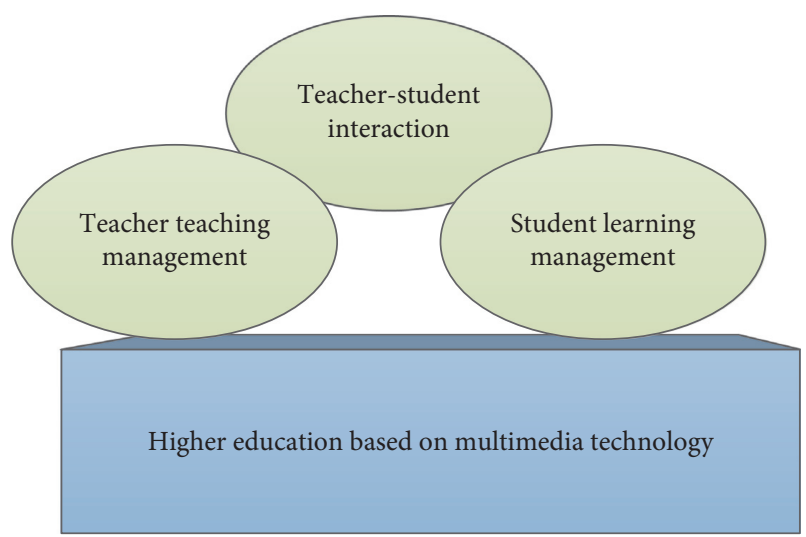

Figure 4: The corresponding frame diagram.

decomposition method, where $\mathbf{U}$ and $\mathbf{C}$ are orthogonal matrices, and

$$
\mathbf{C}=\left(c_{1}, c_{2}, \ldots, c_{n}\right)
$$

wherein $\mathbf{S}$ is an average measure matrix of $\mathbf{L}$, and the elements and eigenvalues of matrix $\mathbf{S}$ satisfy

$$
\begin{array}{r}
\mathbf{S}=\operatorname{diag}\left(\sigma_{1}, \sigma_{2}, \ldots, \sigma_{n}\right), \\
\sigma_{1} \geq \sigma_{2} \geq, \cdots, \geq \sigma_{n} \geq 0 .
\end{array}
$$

The phase space reconstruction locus matrix $\mathbf{L}$ is obtained by calculating the correlation degree, and the scale matrix $\mathbf{X}$ is given by

$$
\mathbf{X}=\left[\begin{array}{c}
\mathbf{x}_{1} \\
\mathbf{x}_{2} \\
\vdots \\
\mathbf{x}_{3}
\end{array}\right]=\left[\begin{array}{cccc}
\mathbf{a}_{1}^{T} \mathbf{c}_{1} & \mathbf{a}_{1}^{T} \mathbf{c}_{2} & \ldots & \mathbf{a}_{1}^{T} \mathbf{c}_{m} \\
\mathbf{a}_{2}^{T} \mathbf{c}_{1} & \mathbf{a}_{2}^{T} \mathbf{c}_{2} & \ldots & \mathbf{a}_{2}^{T} \mathbf{c}_{m} \\
\vdots & \vdots & \ddots & \vdots \\
\mathbf{a}_{N}^{T} \mathbf{c}_{1} & \mathbf{a}_{N}^{T} \mathbf{c}_{2} & \ldots & \mathbf{a}_{N}^{T} \mathbf{c}_{m}
\end{array}\right]
$$

The autocorrelation coefficient of big data information flow scalar time series is obtained as follows:

$$
\rho_{X Y}=\frac{\operatorname{Cov}(X, Y)}{\sqrt{D(X)} \sqrt{D(y)}} .
$$

Based on the sparse iterative covariance estimation of big data information flow, the autocorrelation covariance is obtained as follows: 


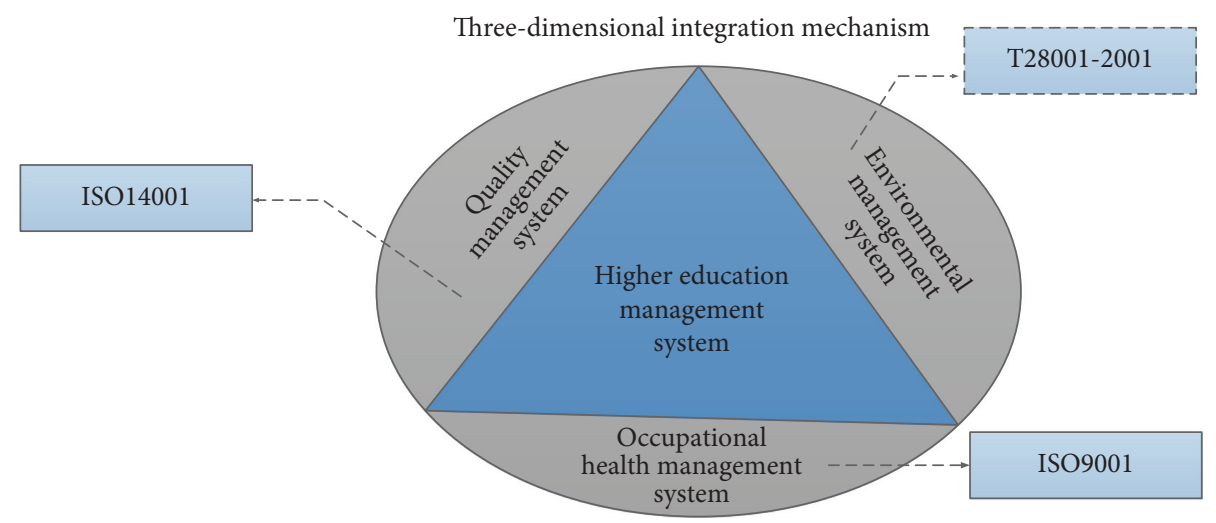

FIgURE 5: The corresponding frame diagram.

$$
\operatorname{Cov}(X, Y)=E\{[X-E(X)][Y-E(Y)]\} .
$$

With the above analysis, the nonlinear time series analysis and phase space reconstruction of big data information flow can be realized.

\subsubsection{Analysis of the Quality Management System of Three-} Dimensional Integrated Education. The three-dimensional integrated higher education management system proposed in this paper mainly contains five parts of understanding. This paper summarizes it as a series of numbers as "12345," in which different numbers correspond to "54321," respectively, and The corresponding explanation is based on the five concepts contained in the three-dimensional integrated concept system; the second is that the corresponding institutional system contains four levels of documents; the third monitoring system forms a three-way monitoring; the corresponding fourth is the technical level, which includes two platforms; the fifth corresponds to a continuous improvement system, which ultimately forms a mechanism. The corresponding concepts are shown in Table 2 .

In the three-dimensional integrated education management system, the system can be compared to the automobile, in which the concept of the system is equal to the steering wheel, which plays a guiding role and has a very important position; the file system at the institutional level is similar to the traffic map and its planning. The route of the car also reflects the connection and limitation of the threedimensional concept in various rules; the monitoring system is like the instrument panel, which reflects the running state of the entire education system in real time; the improved system is similar to the maintenance station and is adjusted in time. Technical support level is similar to the highway, which can ensure the timely, accurate, and efficient information processing of the entire higher education three-dimensional integrated management system. The corresponding logical framework diagram is shown in Figure 6.

The core concept of the three-dimensional integration proposed in this paper is to focus on the students, highlighting the importance of people, taking into account the prevention-oriented, pursuing a scientific management system, taking the facts as the basis for decision-making, and attaching importance to the research role. For the management foundation, it emphasizes the management of higher education system according to law; among them, the management of higher education management system should focus on teaching management, and all mechanisms should serve teaching.

In the three-dimensional integrated management system, three points are observed. One is to cherish and protect the health and safety of teachers and students, and the other is to respect the harmony between nature and society. The third is to provide quality educational products. In the higher education management system based on the threedimensional integration, we must keep the school in harmony with nature, maintain the harmony between teachers and students, maintain the harmony of teaching, research, and management, and achieve a balanced and harmonious relationship between higher campus management and teaching management. In the quality management system of higher education, we must always be aware of the risk factors existing in the management system and conduct preventive assessments to prevent them from happening.

3.1.2. Integration of Multimedia Technologies Based on Higher Education. The three-dimensional integrated education management system proposed in this paper is based on Internet multimedia technology. In addition, the three-dimensional integrated higher education network management mechanism relies heavily on multimedia Internet technology. Based on the theory of this paper, the ecology of the Internet higher education management system can be constructed. The ecology is mainly based on the teaching content of the online course, the quality of education, the education group, and the form of education. In the course of network higher education teaching and the corresponding management system, such as 3D virtual environment technology and multimedia imaging technology, the corresponding application architecture technology is shown in Table 3.

3.2. Diversion Strategy in Higher Education System. The abovementioned problem of the increasing popularity of higher education is that people's demand for higher education is increasingly diversified. view of the dilemmas of my 
TABLE 2: The corresponding concepts.

Three-dimensional integrated system

Concept level

Institutional level

Monitoring level

Technical level

Improvement level
Main content

5: 5 concepts, corresponding to "education as a service," "big teaching quality concept," teaching quality "three-dimensional view," "education quality risk concept," "full quality control concept" 4: management manual, document program, job guidance, record 3: school, student, society

2: management information system and educational administration network system 1: continuous improvement mechanism

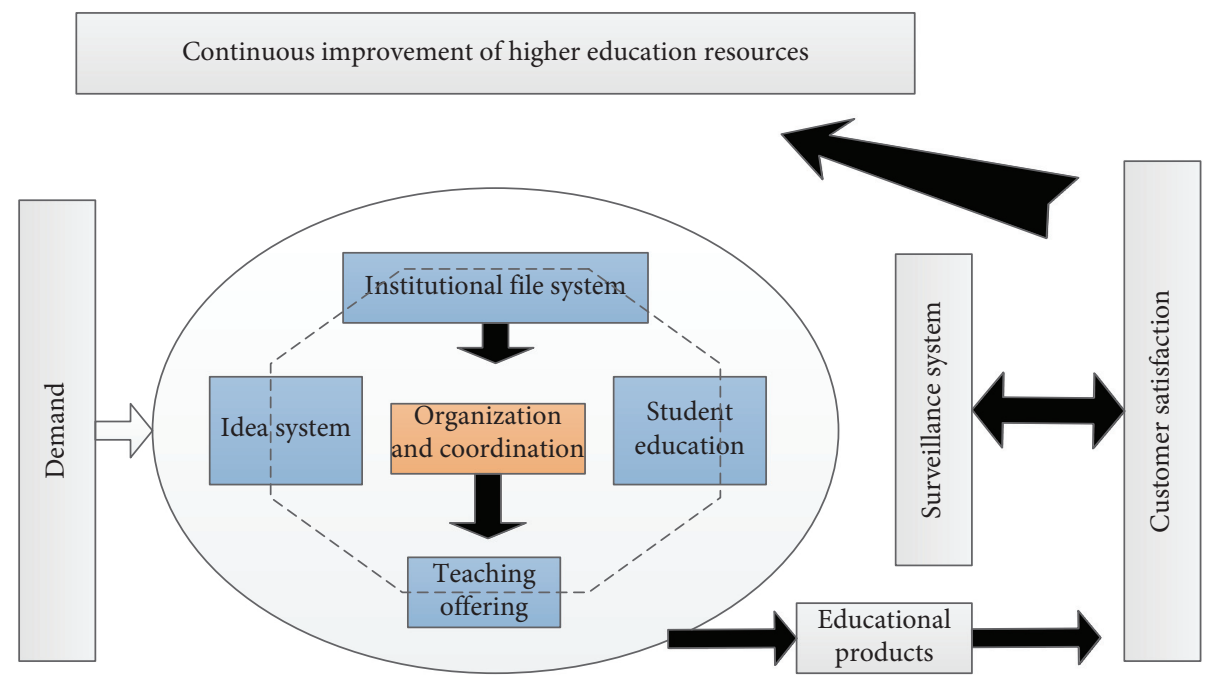

FIGURE 6: The corresponding logical framework diagram.

TABLE 3: Student and translation environment interaction questionnaire.

\begin{tabular}{|c|c|c|}
\hline & Main medium & Multimedia technology application \\
\hline & Before class & Smart device \\
\hline Network higher education system & $\begin{array}{l}\text { In the course } \\
\text { After class }\end{array}$ & $\begin{array}{l}\text { 3D virtual technology, image multimedia technology } \\
\text { Intelligent device, artificial intelligence technology }\end{array}$ \\
\hline
\end{tabular}

country's higher education system, such as low system authority, poor system coordination, and imperfect system operation, this paper proposes a three-level education management mechanism, which classifies and refines the different needs of higher education. The corresponding framework is shown in Figure 7.

In the specific implementation strategy, it is necessary to promote the combination with market induction, promote the combination of top-level design and partial pilot, and combine the moderate breakthrough with steady advancement, and also based on the combination of national conditions and reasonable reference. In the specific implementation details, special laws and regulations should be formulated to promote the authority of the multidirectional diversion system of higher education. It is necessary to improve the horizontal and vertical coordination mechanism, improve the coordination of the multidirectional diversion system of higher education, and actively promote the transformation work and promote higher education. In the implementation of channels, we must actively build multiple communication channels, establish a twoway communication mechanism, and actively improve existing communication mechanisms. In terms of connection, we must actively establish higher vocational education undergraduate level education, develop higher vocational education graduate level, pay attention to top-level design, improve the systemic system, optimize the formulation process, ensure the scientific nature of the system, and enhance the operational efficiency of the system. In terms of legal guarantees, we must actively improve the promotion of legal and legislative work, establish a standard framework covering the whole country, and establish a supporting system for mutual assistance and harmony.

\section{Practice and Analysis}

Based on the abovementioned principle description of the higher education management system based on computer Internet technology and the corresponding analysis and research on its core ideas, this section will carry out the construction and verification analysis of the actual model for the above theory.

Figure 8 shows the corresponding platform block diagram of the higher education management system proposed in this paper. 


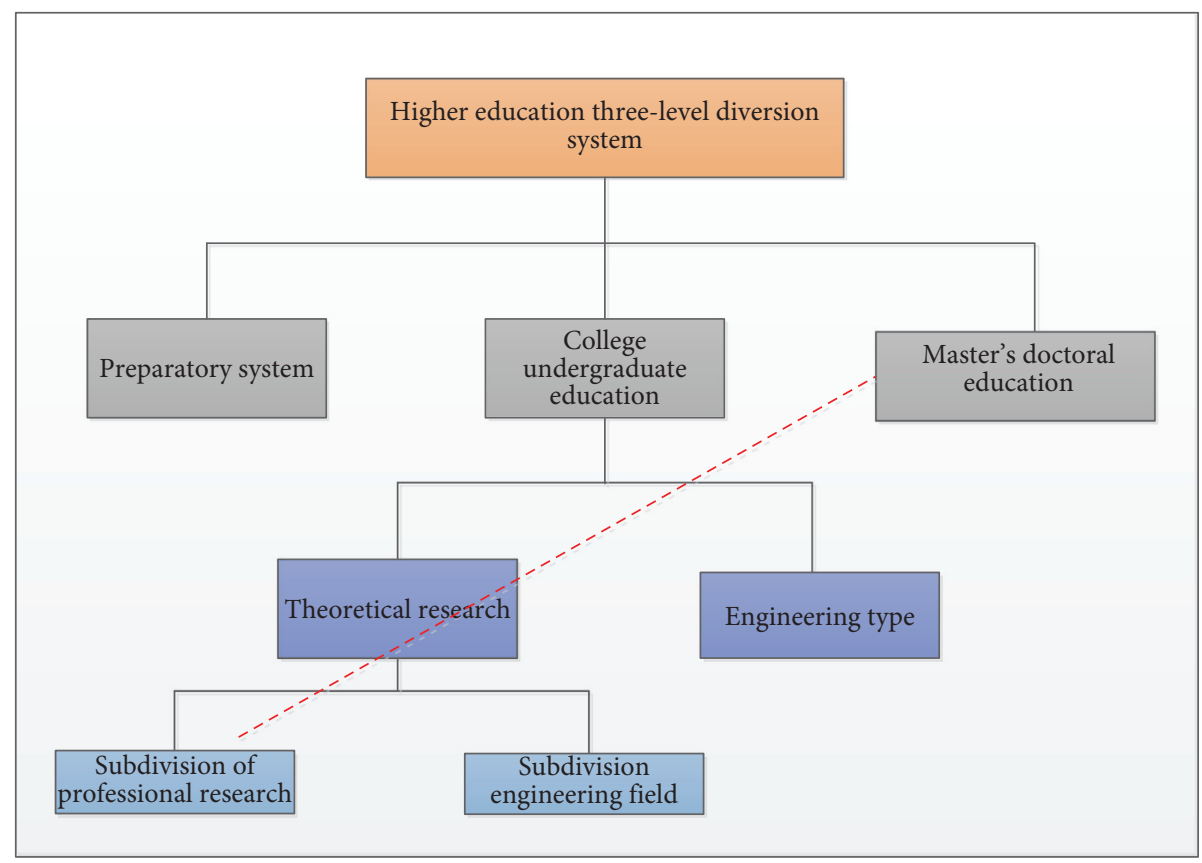

FiguRE 7: The corresponding framework.

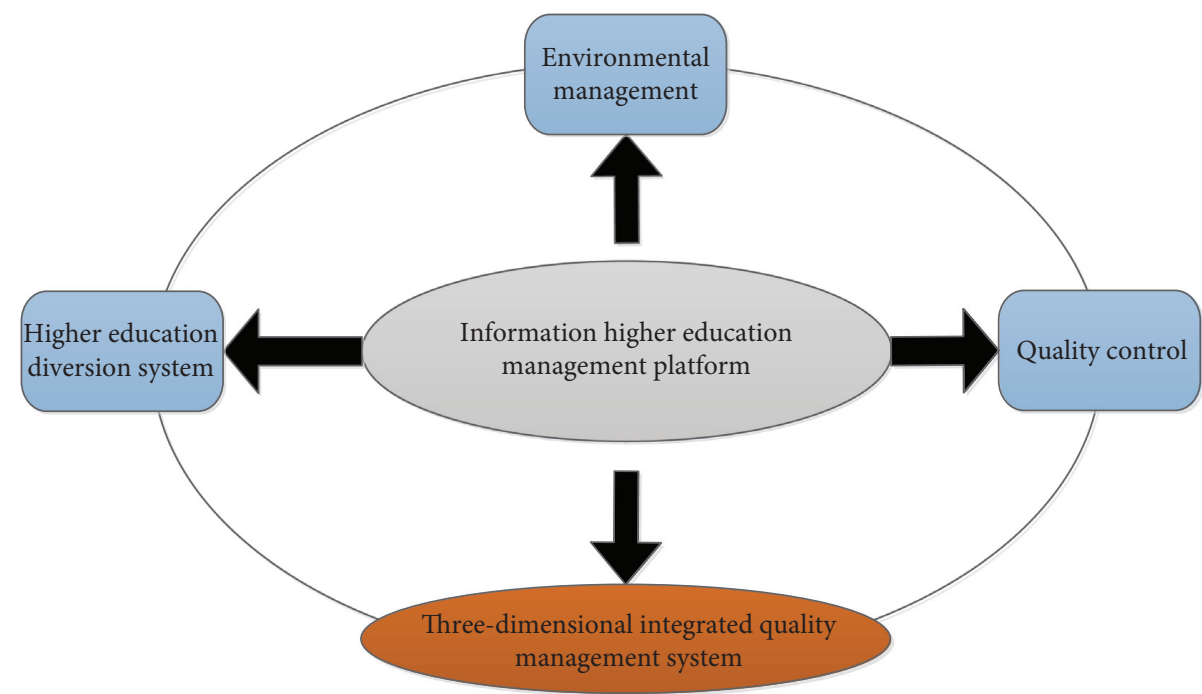

FIGURE 8: The corresponding platform block diagram of the higher education management system.

The corresponding operation mechanism is shown in Figure 9. In the actual operation process, the core idea of three-dimensional integration is always adhered to, and the operation system is monitored throughout the whole process. In practical application, the detailed process of higher education operation in the management system should be analyzed. Through process control to ensure that the quality is guaranteed, while correspondingly affecting the quality of education and the smooth operation of the system, in the aspect of the education subfluid system, it is necessary to pay attention to the policy of top-level design in a timely manner. The corresponding five management mechanisms are the teaching work management mechanism, the student work management mechanism, the scientific research work management mechanism, the school work management mechanism, and the logistics support management. The mechanism will be coordinated and fully utilized to give full play to the advantages and potential of the three-level diversion system.

Based on the analysis and establishment of the above theoretical model, this paper conducts a practical questionnaire analysis on the higher education management mechanism based on multimedia technology proposed in this paper. The corresponding data table is shown in Table 4. It can be seen from the table that it is certain. To a certain extent, it reflects the acceptance of the management mechanism proposed in this paper. The corresponding sample of the questionnaire is 4000 . The corresponding 


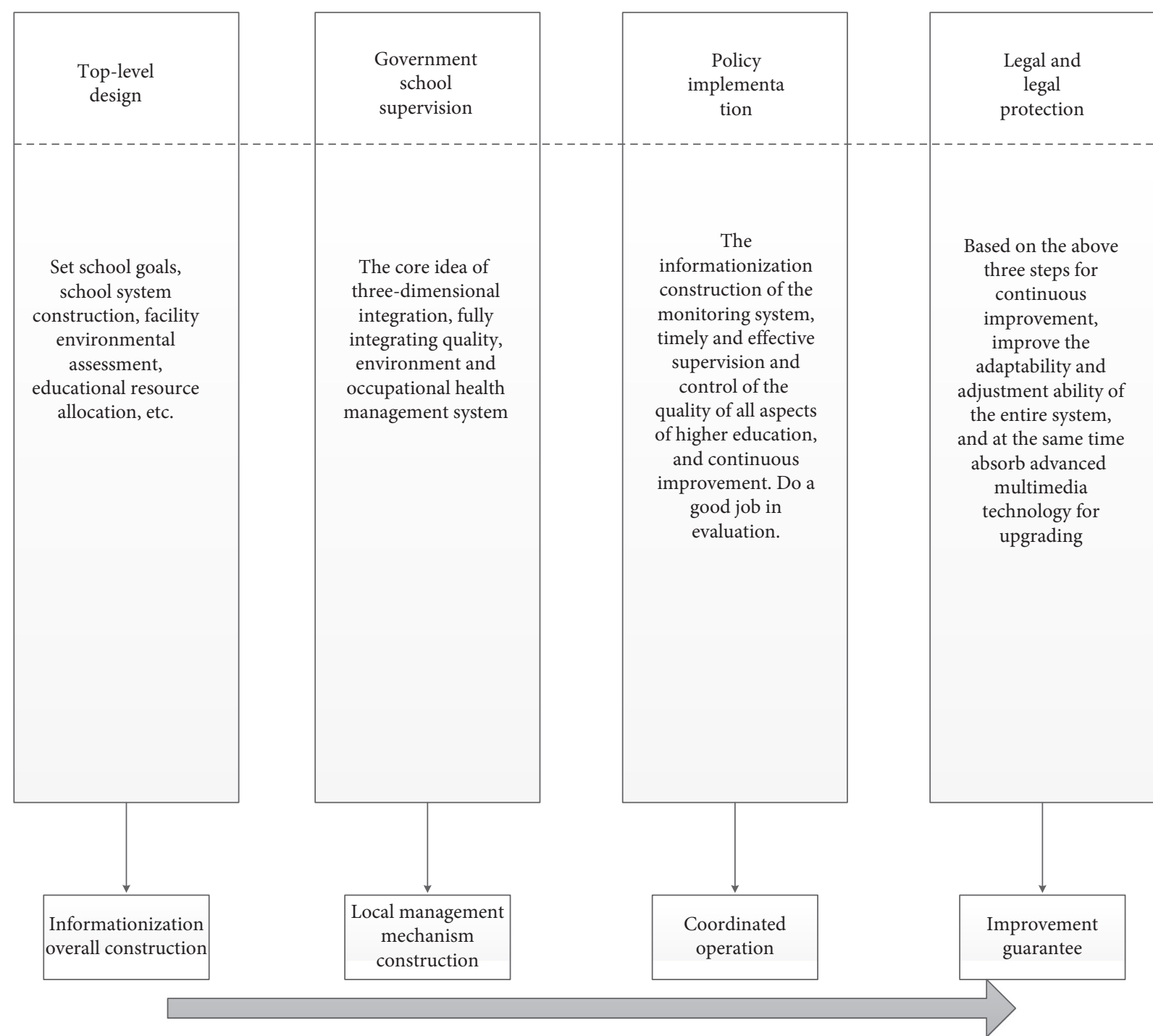

FIgURE 9: The corresponding operation mechanism.

TABle 4: The corresponding data table.

\begin{tabular}{|c|c|c|c|}
\hline $\begin{array}{l}\text { Total number of } \\
\text { samples }\end{array}$ & Option & $\begin{array}{l}\text { Proportion } \\
\quad(\%)\end{array}$ & Conclusion \\
\hline \multirow{4}{*}{4000} & $\begin{array}{l}\text { Fully accepted and expect a good } \\
\text { form to appear }\end{array}$ & 78 & \multirow{4}{*}{$\begin{array}{c}\text { On the whole, I tend to look forward to the emergence of a new } \\
\text { higher education management system }\end{array}$} \\
\hline & Accept but stay optimistic & 15 & \\
\hline & No feeling is not important & 3 & \\
\hline & $\begin{array}{c}\text { Do not expect to feel the current } \\
\text { problem }\end{array}$ & 4 & \\
\hline
\end{tabular}

population includes teachers, students, and related educators, covering the eastern and western regions in the coverage area.
The corresponding actual number of people is shown in Figure 10. From the bar chart, the higher education management system based on Internet multimedia 


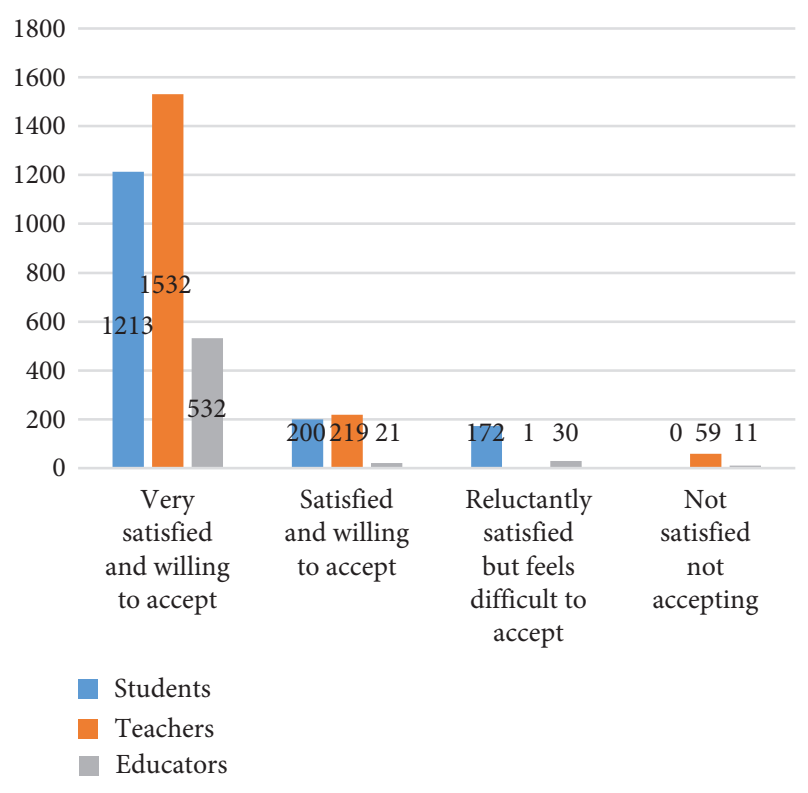

Figure 10: The corresponding histogram.

technology proposed in this paper has been recognized and paid attention.

\section{Conclusion}

With the improvement of China's economy and the implementation of the education first policy, the spread of higher education has made excessive successes in China. This paper proposes an online education management system based on Internet multimedia technology, which realizes the network management of education through computer technology. At the same time, aiming at the urgent needs of the current lifelong education of higher education, a reasonable system of higher education diversion is established to focus on solving the phenomenon of imbalanced proportions, ambiguous functions, and low communication efficiency. In the final practical part of this paper, the system model of the three-dimensional integrated education system and the corresponding practical solution to the education diversion are given. After discussion, it has practical application value. The results of the research have shown the effectiveness of the proposed study.

\section{Data Availability}

The data used to support the findings of this study are available from the corresponding author upon request.

\section{Conflicts of Interest}

The authors declare that they have no conflicts of interest.

\section{Acknowledgments}

This study was supported by the general project of philosophy and social science research of Jiangsu University in 2019 "on the strategy of Zhenjiang higher vocational education industry education integration and school-enterprise cooperation innovation platform under the background of vocational education reform (no. 2019sja1951)" and Science and Technology Project of Jiangsu Vocational College of Agriculture and Forestry in 2019 "Research on the Development Countermeasures of Zhenjiang Higher Vocational Education Cooperative Innovation and School Enterprise Cooperative Education (no. 2019kj023)”.

\section{References}

[1] S. B. Dias and J. A. Diniz, "Towards an enhanced learning management system for blended learning in higher education incorporating distinct learners' profiles," Journal of Educational Technology \& Society, vol. 17, no. 1, pp. 307-319, 2014.

[2] A. Decramer, C. Smolders, and A. Vanderstraeten, "Employee performance management culture and system features in higher education: relationship with employee performance management satisfaction," The International Journal of $\mathrm{Hu}$ man Resource Management, vol. 24, no. 2, pp. 352-371, 2013.

[3] J. Dalling and P. Rafferty, "Open source, open minds?: An investigation into attitudes towards open source library management systems in UK higher education libraries," Program-electronic Library and Information Systems, vol. 47, no. 4, pp. 399-423, 2013.

[4] J. B. Abugre, "Institutional governance and management systems in sub-Saharan Africa higher education: developments and challenges in a Ghanaian research university," Higher Education, vol. 75, no. 2, pp. 323-339, 2017.

[5] K. A. Al-Busaidi and H. Al-Shihi, "Key factors to instructors' satisfaction of learning management systems in blended learning," Journal of Computing in Higher Education, vol. 24, no. 1, pp. 18-39, 2012.

[6] A. Clarke, "The campus environmental management system cycle in practice: 15 years of environmental management, education and research at Dalhousie University," International Journal of Sustainability in Higher Education, vol. 7, no. 4, pp. 374-389, 2006.

[7] W. Y. W. Lo, "The recalibration of neoliberalisation: repoliticising higher education policy in Hong Kong," Higher Education, vol. 73, no. 5, pp. 759-773, 2017.

[8] A. Smolentseva, "Universal higher education and positional advantage: soviet legacies and neoliberal transformations in Russia," Higher Education, vol. 73, no. 2, pp. 209-226, 2017.

[9] A. Bagerelsborg and L. Greve, "Establishing a method for analysing metaphors in higher education teaching: a case from business management teaching," Higher Education Research \& Development, vol. 38, no. 7, pp. 1329-1342, 2017.

[10] P. A. M. Maassen and H. P. Potman, "Strategic decision making in higher education: an analysis of the new planning system in Dutch higher education," Higher Education, vol. 20, no. 4, pp. 393-410, 2017.

[11] J. Mampaey, J. Brankovic, and J. Huisman, "Inter-institutional differences in defensive stakeholder management in higher education: the case of Serbia," Studies in Higher Education, vol. 44, no. 6, pp. 978-989, 2017.

[12] M. Seyfried and M. Ansmann, "Unfreezing higher education institutions? Understanding the introduction of quality management in teaching and learning in Germany," Higher Education, vol. 75, no. 6, pp. 1061-1076, 2018.

[13] C. C. Hsieh and J. Huisman, "Higher education policy change in the European higher education area: divergence of quality 
assurance systems in England and the Netherlands," Research Papers in Education, vol. 32, no. 1, pp. 71-83, 2017.

[14] M. Ekman, M. Lindgren, and J. Packendorff, "Universities need leadership, academics need management: discursive tensions and voids in the deregulation of Swedish higher education legislation," Higher Education, vol. 75, no. 2, pp. 299-321, 2017.

[15] B. Broucker, K. D. Wit, and J. C. Verhoeven, "Higher education for public value: taking the debate beyond new public management," Higher Education Research \& Development, vol. 37, no. 2, pp. 227-240, 2017.

[16] A. Parvin, "Leadership and management in quality assurance: insights from the context of Khulna university, Bangladesh," Higher Education, vol. 77, no. 2, pp. 739-756, 2018.

[17] N. Dreamson, G. Thomas, A. L. Hong, and S. Kim, "Policies on and practices of cultural inclusivity in learning management systems: perspectives of Indigenous holistic pedagogies," Higher Education Research \& Development, vol. 36, no. 5, pp. 947-961, 2016.

[18] F. Marimon, M. Masmachuca, and J. Berbegalmirabent, "Fulfilment of expectations on students' perceived quality in the Catalan higher education system," Total Quality Management \& Business Excellence, vol. 31, no. 5, pp. 483-507, 2018. 